\title{
Managing information complexity using system dynamics on construction projects
}

Article

Accepted Version

Khan, K. I. A., Flanagan, R. and Lu, S.-L. (2016) Managing information complexity using system dynamics on construction projects. Construction Management and Economics, 34 (3). pp. 192-204. ISSN 0144-6193 doi:

https://doi.org/10.1080/01446193.2016.1190026 Available at https://centaur.reading.ac.uk/65787/

It is advisable to refer to the publisher's version if you intend to cite from the work. See Guidance on citing.

Published version at: http://www.tandfonline.com/doi/full/10.1080/01446193.2016.1190026

To link to this article DOI: http://dx.doi.org/10.1080/01446193.2016.1190026

Publisher: Taylor \& Francis

All outputs in CentAUR are protected by Intellectual Property Rights law, including copyright law. Copyright and IPR is retained by the creators or other copyright holders. Terms and conditions for use of this material are defined in the End User Agreement.

\section{www.reading.ac.uk/centaur}

\section{CentAUR}

Central Archive at the University of Reading 
Reading's research outputs online 


\title{
Managing Information Complexity using System Dynamics on Construction Projects
}

\author{
KHURRAM IQBAL AHMAD KHAN ${ }^{\text {a }}$, ROGER FLANAGAN ${ }^{\text {a }}$ and SHU-LING LU ${ }^{\mathrm{a}}$ \\ School of Construction Management and Engineering, University of Reading, Reading, UK
}

The increase in e-commerce, the digitisation of design data, and the interchange and sharing of information has made the construction sector more reliant upon IT infrastructure and systems. The design and production process is complex, dynamic, interconnected, and dependent upon greater information mobility, requiring seamless exchange of data and information in real-time. Small and medium-sized enterprises (SMEs), in particular, the specialty contractors, can utilise cost-effective collaboration technologies, such as cloud computing using software as a service, to help in the effective transfer of information and data. The system dynamics (SD) approach gives a better understanding of the dynamics of complex systems. SD methodology is used as a modelling and analysis tool, to understand and identify the key drivers in the absorption of cloud computing for SMEs. The aim is to determine how the use of SD can improve the management of complexity of information flow, leading to improved performance for SMEs. SD is shown to be a viable tool to manage information complexity using cloud computing for performance improvement in construction.

Keywords: system dynamics (SD), small and medium-sized enterprises (SMEs), information mobility, performance improvement, cloud computing. 
[To cite this article: Khurram lqbal Ahmad Khan, Roger Flanagan \& Shu-Ling Lu (2016), Managing information complexity using system dynamics on construction projects, Construction Management and Economics, DOI: 10.1080/01446193.2016.1190026]

\section{Introduction}

The construction sector is fragmented, project based (and therefore mobile/temporary), with many types of information needed by different stakeholders (Betts 1999), including clients, regulatory authorities, consultants, contractors and the supply chain. Information flow is the backbone for all successful projects across the construction sector; improved information flow across different stakeholders leads to better performance. There is a need for increased information mobility that offers seamless exchange of information in real-time (McGraw-Hill Construction 2013). Small and medium-sized enterprises (SMEs) are an important part of the UK construction sector; they need to absorb technologies for enabling collaboration. Cloud computing provides a platform for cloud collaboration tools, facilitating transfer of information and data in digital format using digital devices such as smart phones, tablets, phablets and laptops on construction sites. The aim of the research is to consider how system dynamics provides a basis for understanding the management of complexity for the accessibility to information by SMEs that can improve efficiency, performance, and productivity. Productivity is the ratio of a measure of output to a measure of some, or all of the resources, used to produce this output (Grimes 2006). Productivity improvement is an increase in the ratio of produced goods or services in relation to resources utilised (Pekuri et al. 2011). Performance improvement embodies productivity and service quality, and delivery.

Construction projects are characterised by complexity in both design and production. There is interaction between order and disorder, predictability and unpredictability, regularity and chaos, which are innate characteristics of complex systems. Complex systems thrive in the real world, reflecting the world's inherent irregularity. Construction is a world of complexity, of messiness, of change, flow and process, and cannot be associated with simplicity, solidity 
[To cite this article: Khurram lqbal Ahmad Khan, Roger Flanagan \& Shu-Ling Lu (2016), Managing information complexity using system dynamics on construction projects, Construction Management and Economics, DOI: 10.1080/01446193.2016.1190026]

and unchanging objects (Merry and Kassavin 1995). The paper consists of; (1) development of a system dynamics model to address information complexity for productivity improvement for SMEs; and (2) the development of a conceptual framework to improve the work packages information flow and feedback for SMEs using a system dynamics approach at the site production phase.

System dynamics is a tool to address complexity in the management of information flow using non-linear feedback on construction sites. The research investigates system dynamics (SD) methodology as a modelling and analysis tool to identify key drivers in the absorption of cloud computing by SMEs.

Consideration is given to information flow through the value chain from the design team to the specialty contractor, focusing upon the specialty contractor. Most research has been concerned with information flow between the design team and the main/principal contractor, whereas with specialisation and the outsourcing of work packages, the role of the specialty contractors is increasingly important in the information flow process.

\section{The need for information mobility}

The research has focussed on project information, which includes models, drawings, emails, mark-ups, requests for information, transmittals, meeting minutes, images, contracts, specifications, change orders, payments, and other documentation created in the course of designing, building and operating facilities. Information and data moves from the design offices to the construction site, where the design converts into production involving a plethora of different skills and trades. The specialty contractor focusses on their work package; requiring different production information to fulfil the work package, with the 
[To cite this article: Khurram lqbal Ahmad Khan, Roger Flanagan \& Shu-Ling Lu (2016), Managing information complexity using system dynamics on construction projects, Construction Management and Economics, DOI: 10.1080/01446193.2016.1190026]

main/principal contractor co-ordinating and managing such information and data. The specialty contractors care about safety, delivery on time and within budget, payment, and profitability. The specialty contractor must deal with requests for information, change orders, materials delivery, resource availability, and method and sequence of work. Chen and Kamara (2008) considered information management on construction sites, they concluded that there is generally a paucity of information and data on construction sites. However, this finding is an over-simplification; the challenge is for relevant, timely, and appropriate information for the specialty contractors. Drawings show layouts and elevations, not production method, or sequence of activities. Because of complexity, the project information and data is frequently of variable degrees of accuracy, and reliability.

Computer Aided Design (CAD) and Building Information Modelling (BIM) has made the design process more dynamic, with faster reaction times on projects. On-time and accurate information provided during the production phase reduces errors, rework, and delays, reducing the likelihood of contractual claims, disputes, and the requirement for change orders. Timely information and communication contributes towards improved health and safety on construction sites (HSE 2002), and helps in completing projects on time, with reduced costs and improved quality (Titus and Bröchner 2005). Moreover, information in real-time about external factors that influence production, such as delays caused by exceptionally inclement weather, unexpected events, or a significant design change being proposed by the client and design team, can help plan activities and minimise disruption to production. The information is non-linear and dynamic which involves processing complexity. The management of the complexity of information flow on construction sites is, therefore, important for all the stakeholders in the production delivery chain. 
[To cite this article: Khurram lqbal Ahmad Khan, Roger Flanagan \& Shu-Ling Lu (2016), Managing information complexity using system dynamics on construction projects, Construction Management and Economics, DOI: 10.1080/01446193.2016.1190026]

This research takes a bottom-up approach, viewing production from the site team's perspective. Effective collaboration between all organisations involved in a project has become a fundamental requirement in construction. Collaboration tools provide document access across any endpoint, deepen connections with partners, and improve productivity. Technologies for enabling collaboration provide a platform for software collaboration tools that can improve information mobility and data transfer. 'Information mobility' is about ensuring seamless exchange of information in the right version, in the appropriate format, and with the required level of reliability, accessed by the right people, at the right time (McGrawHill Construction 2013). The users are as important to information mobility as the technology; mobility will depend on the user's motivation, whether they can afford to use it, and if they have the ability to do so (Peters 2004).

\section{Characteristics and importance of UK SMEs}

The Department for Business Innovation \& Skills (BIS) (2014) define small and mediumsized enterprises (SMEs) as businesses with 0-249 employees. SMEs account for $99.8 \%$ of all UK businesses, $60 \%$ of employment, and $47 \%$ of annual turnover. Construction SMEs are $18.12 \%$ of all UK SME businesses, with $85 \%$ of employment, and $73 \%$ of turnover in the UK construction sector (BIS 2014).

For an SME, the productive activity represents the heart of the organisation (Di Tommaso and Dubbini 2000). This led the research to focus on the firm's productive capacity and capability on the construction site. Sexton and Barrett (2003a) identified four unique characteristics of construction SMEs: 
[To cite this article: Khurram lqbal Ahmad Khan, Roger Flanagan \& Shu-Ling Lu (2016), Managing information complexity using system dynamics on construction projects, Construction Management and Economics, DOI: 10.1080/01446193.2016.1190026]

1. Limited staff capacity as well as capability restricting their ability to undertake necessary research and development (R\&D).

2. Limited time and resources for external interaction that results in restricted flow and amount of information.

3. Dominated by single owner or a small team who may use inappropriate strategies and skills.

4. Difficulty in maintaining adequate cash flow that results in limited scope for capital, or on-going investment in innovation activity.

The research identified two further characteristics, firstly, the lack of systems and procedures with feedback loops providing real-time information on performance. Secondly, lack of formal organisational structures leading to poor systems integration across the business. SMEs work on both small and large projects as main contractors, sub-contractors, or specialty contractors. Large organisations outsource to reduce overhead costs (Langford and Male 1991), leading to an increase in the use and number of specialty contractors. Such an increase requires more information and document management with increased integration across all the stakeholders, including consultants and contractors.

\section{Cloud computing: a technology for enabling collaboration}

There is an absence of a consensual definition of cloud computing (Han and Gani 2012). The most commonly used definition by the US National Institute of Standards and Technology (NIST) is:

a model for enabling ubiquitous, convenient, on-demand network access to a shared pool of configurable computing resources (e.g. 
[To cite this article: Khurram lqbal Ahmad Khan, Roger Flanagan \& Shu-Ling Lu (2016), Managing information complexity using system dynamics on construction projects, Construction Management and Economics, DOI: 10.1080/01446193.2016.1190026]

networks, servers, storage, applications and services) that can be rapidly provisioned and released with minimal management effort or service provider interaction (Mell and Grance 2011, p.2).

Cloud computing is a general term for anything that includes providing hosted services over the internet (Beach et al. 2013), where everything is treated as a service (XaaS) e.g. SaaS (Software as a Service), PaaS (Platform as a Service) and IaaS (Infrastructure as a Service). These services define a layered system structure for cloud computing (Pallis 2010):

1. Infrastructure as a Service (IaaS): At the 'infrastructure layer', processing, storage, networks, and other fundamental computing resources are defined as standardised services over the network. Cloud providers' clients can deploy and run operating systems and software for their underlying infrastructure.

2. Platform as a Service (PaaS): The 'middle layer' provides abstractions and services for developing, testing, deploying, hosting, and maintaining applications in the integrated development environment.

3. Software as a Service (SaaS): The 'application layer' provides a complete application set of SaaS. The 'user interface' layer at the top enables seamless interaction with all the underlying XaaS layers.

Cloud computing consists of four deployment models for cloud infrastructure (Mell and Grance 2011):

1. Private cloud: for exclusive use by a single organisation.

2. Community cloud: for exclusive use by specific community of consumers from organisations that have shared concerns. 
[To cite this article: Khurram lqbal Ahmad Khan, Roger Flanagan \& Shu-Ling Lu (2016), Managing information complexity using system dynamics on construction projects, Construction Management and Economics, DOI: 10.1080/01446193.2016.1190026]

3. Public cloud: for open use by the general public.

4. Hybrid cloud: consisting of two or more cloud infrastructures (private, community or public cloud) that remain unique entities, but are bound together.

Information Technology (IT) is a major tool in construction performance improvement (Marsh and Flanagan 2000). Construction organisations increasingly use IT to support their business strategies (Andresen 2000). There is concerted effort to explore and implement existing and emerging IT technologies to facilitate improvements required to modernise the construction sector (Bowden et al. 2006).

The absorption of IT technologies remains low, due mainly to the lack of human and financial resources required to use and maintain IT investment (Cheng and Kumar 2012). SMEs display a general lack of awareness and indifferent attitude towards new IT. Cloud computing is an emerging technology that is both innovative and cost-effective. The main drivers of cloud computing include cost, simplification, and convenience. It can make use of the existing IT infrastructure to get access to computing resources that can be configured according to the requirements of the organisation, with pay-as-you-go payment.

Cheng and Kumar (2012) identify challenges in the absorption of cloud computing, such as concerns about data security, performance, and availability of service; an unstable bandwidth and internet connection can adversely affect the cloud-based systems and applications, thus affecting construction personnel working on site. Advancements in technology and satellite coverage, and availability and stability of web connection will be improved in future (Cheng and Kumar 2012). 
[To cite this article: Khurram lqbal Ahmad Khan, Roger Flanagan \& Shu-Ling Lu (2016), Managing information complexity using system dynamics on construction projects, Construction Management and Economics, DOI: 10.1080/01446193.2016.1190026]

SMEs can adopt the Hybrid-SaaS model, with a combination of public and private cloud, which provides opportunities to store data on an 'on - premise' server managed by the organisation, and providing opportunities to use the cloud (Juan and Zheng 2014). The Hybrid-SaaS model facilitates both the specialty contractor, and the main contractor to regulate accessibility to information, allowing only the relevant project information to be accessible to all the concerned parties and the construction site personnel. There are many cloud collaboration tools, including Microsoft One Drive, Google Drive, iCloud Drive, Huddle, Evernote and Dropbox. Information is accessed through cloud collaboration tools using digital devices such as smart phones, tablets, phablets and laptops on construction sites. Digitisation has meant the availability of more information, leading to greater complexity and interconnectivity, with the need to understand and address complexity.

\section{Complexity science and the dynamics of the construction sector}

Complexity theory and science deals with complex systems. However, there is no consensus on a clear, and precise definition of the concept of complexity (Morel and Ramanujam 1999, Bertelsen 2003a, Wood and Gidado 2008, Bawden and Robinson 2015). Complexity science studies how relationships between parts give rise to the collective behaviours of a system and how the system interacts and forms relationships with its environment (Wood and Gidado 2008). Such interactions are associated with the presence of feedback mechanisms in the system (Morel and Ramanujam 1999, Bertelsen 2003b, Ramalingam et al. 2008). Richardson et al. (2000) suggested that the overall message from the complexity science literature is that the interaction between parts of the system determine the identity to the whole system.

Bertelsen (2003a) describes construction as a complex system and explains that the general assumption in planning the construction process is that it is an ordered, linear process, which 
[To cite this article: Khurram lqbal Ahmad Khan, Roger Flanagan \& Shu-Ling Lu (2016), Managing information complexity using system dynamics on construction projects, Construction Management and Economics, DOI: 10.1080/01446193.2016.1190026]

can be organised, planned and managed top down. The frequent failures to complete construction projects on time and schedule give rise to thinking that the process might not be as predictable as it may seem. Construction is a nonlinear, complex and dynamic process. Baccarini (1996) proposes a definition of complexity of construction projects as consisting of many varied interrelated parts that can be operationalised with differentiation and interdependency. He suggests the definition can be applied to any project dimension, such as organisation, technology, environment, information, decision-making and systems, with the need to identify the type of complexity being taken into consideration. Systems thinking is a way of understanding complexity.

\section{Systems thinking and complexity}

Systems thinking is the art and science of making reliable inferences about behaviour by developing deep understanding of underlying structure (Richmond 1994). Systems thinking is close in its origins and scope to complexity theory. Complexity can only emerge in the context of a system. There are certain features of complexity, such as feedback, which are evident in systems thinking (Ramalingam et al. 2008). Senge (1990) proposed that systems thinking looks at the interrelationships, rather than linear cause-effect chains, and the processes of change, rather than snapshots. This leads to a search for certain types of systems structures that recur again and again: the deeper patterns lying behind events and details (Ramalingam et al. 2008). Systems thinking is an effective method to understand and address complexity by focussing on the whole, rather than individual elements of a system. 
[To cite this article: Khurram lqbal Ahmad Khan, Roger Flanagan \& Shu-Ling Lu (2016), Managing information complexity using system dynamics on construction projects, Construction Management and Economics, DOI: 10.1080/01446193.2016.1190026]

\section{System dynamics}

System dynamics is a method to enhance learning in complex systems and tools that enable a better understanding of the dynamics of complex systems (Sterman 2001, Dangerfield et al. 2010). It has the ability to address complexity involving interactive modelling, tools for the representation of feedback structure, and simulation software. SD was developed by Forrester (1961) to reflect the view that the dynamics of industrial systems result from underlying the structure of flows, delays, information and feedback (Dangerfield et al. 2010). Mathematical models of the relations between system components are constructed and computer simulation can help to optimise the system.

System dynamics is interdisciplinary, it is grounded in the theory of non-linear dynamics and feedback control developed in mathematics, physics, and engineering. These tools are applied to the behaviour of human, as well as technical systems. It draws on cognitive and social psychology, organisation theory, economics, and other social sciences to solve important real world problems (Sterman 2000, 2002). System dynamics is criticised due to the inabilities of models to mimic reality (Keys 1990, Hayden 2006). Nevertheless, it has been widely accepted within the field of system dynamics that models are not designed to, and cannot perfectly imitate the real world (Lane 2000, Forrester 2003). Instead, the goal of modelling in system dynamics is to understand the internal systemic structure of a system that drives behaviour (Senge 1990, Sterman 2000).

System dynamics approach has the ability to create 'micro worlds' that present real world issues in a manner that are simple, practical, structured, and comprehensible. The strength is in the ability to break down complex systems into comprehendible sub-systems. SD addresses complexity and process relationships based on non-linear feedback systems. It can 
[To cite this article: Khurram lqbal Ahmad Khan, Roger Flanagan \& Shu-Ling Lu (2016), Managing information complexity using system dynamics on construction projects, Construction Management and Economics, DOI: 10.1080/01446193.2016.1190026]

help improve information flow, through collaboration technologies leading to improved productivity.

\section{Research method and design}

The research was undertaken in two phases (see Figure 1); (phase1) the development of system dynamics model to address information complexity for SMEs; (phase 2) development of a conceptual framework to improve work packages information flow and feedback for SMEs using a system dynamics approach.

$<<$ Insert Figure 1 here >>

\section{Phase 1: Development of system dynamics model}

Information management and challenges faced in the transfer of information and data during the production phase for SMEs for performance improvement, led to the following research question:

How can the use of system dynamics (SD) improve the management of complexity of information flow, resulting in performance improvement for SMEs?

A selected sample of five SME companies was chosen because of their breadth of activities in more than one specialisation, and their willingness to engage and supply detailed information for the research. They received a detailed questionnaire, followed by in-depth interviews. The unit of analysis was longitudinal at the firm level. Data collection involved the level of awareness / knowledge of IT collaboration technologies, in particular, cloud computing. It included benefits and concerns for the absorption of the relevant technology, 
[To cite this article: Khurram lqbal Ahmad Khan, Roger Flanagan \& Shu-Ling Lu (2016), Managing information complexity using system dynamics on construction projects, Construction Management and Economics, DOI: 10.1080/01446193.2016.1190026]

and questions about the status and use of IT in SMEs. Consideration was given to the challenges of effective information management during the production phase, and how the stakeholders transferred information and data about the design to the specialty SME contractors.

The data analysis showed a low level of awareness / knowledge of cloud computing and lack of investment in IT by SMEs. It also highlighted important themes about the challenges of information management faced by the SMEs.

The findings were used to develop data flow diagrams (DFDs). DFDs show relationships among and between the various components in a program or system (Le Vie and Donald 2000). The DFDs were used as a research tool, mapping the information and data flow among stakeholders from design to production, with particular focus on the production phase for SMEs. A lack of feedback systems was identified and the need for improved document management using collaboration technologies for performance improvement for SMEs.

Process maps were developed from the DFDs. Process mapping is an analytical and communication tool to improve existing processes, or to implement a new process-driven structure in order to re-engineer businesses (Hunt 1996). The process maps comprised the 'As-Is' process map showing the existing status highlighting inefficiencies, including the challenges faced by the SMEs in information management. The 'As-Is' process map was followed by the development of the 'To-Be' process map which proposes how existing processes may be improved. It showed the need to improve information complexity. The data from the process maps were analysed and categorised into groups (see the 'Mapping the construction process' below), they were used to operationalise the system dynamics (SD) model. 
[To cite this article: Khurram lqbal Ahmad Khan, Roger Flanagan \& Shu-Ling Lu (2016), Managing information complexity using system dynamics on construction projects, Construction Management and Economics, DOI: 10.1080/01446193.2016.1190026]

The systems dynamics approach was used to develop a causal loop diagram (CLD) and system dynamics model. A focus group, consisting of the participants from each SME in the interview sample, was used to test and validate the model.

\section{Phase 2: Development of a conceptual framework for SMEs}

A conceptual framework was developed from the system dynamics model for work packages information. The aim of the framework was to improve the specialty contractors' performance by better management of information and data on projects. Miles and Huberman (1994) define a conceptual framework as a visual or written piece of work, which elaborates in either graphical or narrative form the main things that need to be studied - the key factors, constructs or variables - and the recognised relationships among them. The conceptual framework was validated using the focus group.

\section{Mapping the construction process}

The findings are listed below are categorised as 'Factors', 'Enablers' and 'Production'. The 'Factors' are issues faced by SMEs; the participants described the increasingly complex nature of the construction sector with many interdependencies. The 'Enablers' lists important tools that have the ability to address the issues in the 'Factors' category. The 'Production' category lists the elements directly affected by the 'Factors' affecting both the construction project, and the specialty contractors.

\section{Factors}

- Lack of formal systems and structures to manage information

- Lack of integration due to poor management and quality of information flow among stakeholders 
[To cite this article: Khurram lqbal Ahmad Khan, Roger Flanagan \& Shu-Ling Lu (2016), Managing information complexity using system dynamics on construction projects, Construction Management and Economics, DOI: 10.1080/01446193.2016.1190026]

- Lack of integration between stakeholders to share information

- Failure to learn from past experience caused by a lack of formal feedback systems

- Interdependency between the specialty contractors not recognised by the design team

- Complexity of the production process

- Inadequate sequence and timing of information

- Lack of formal feedback systems from site performance to planning and estimating

- Lack of timely payments, chasing payments, lack of effective cash flow management

- Inadequate pre-planning and production planning by the specialty contractor

- Lack of detailed information provided by design team for the specialty contractor

- Decline in quality and quantity of information provided by design team over the past 5 years

- Contract conditions - lack of detailed awareness of contract conditions in the main contract that the specialty contractor must adhere to

- Lack of document management

- Lack of real-time information

- Lack of investment in IT by SMEs

- Absence of robust digital infrastructure on job sites

\section{Enablers}

- Systems thinking

- System dynamics

- Cloud computing technology

- Cloud collaboration tools

\section{Production}

- Management of cost, payments, cash flow, cost/value reconciliation 
[To cite this article: Khurram lqbal Ahmad Khan, Roger Flanagan \& Shu-Ling Lu (2016), Managing information complexity using system dynamics on construction projects, Construction Management and Economics, DOI: 10.1080/01446193.2016.1190026]

- Management of time

- Resources (human and financial), resource scheduling to ensure continuity

- Quality assurance and control

- Contractual (legal)

- Health, safety, and well-being of the workforce on site

- Planning of the work packages, production planning, and temporary works design, statutory compliance requirements

- Management of plant and equipment, and tools

- Materials management and delivery schedules to ensure continuity of the work package

- Impact of weather and temporary protection

- Feedback about performance

A major failing in many systems is the influence of complexity, and the lack of feedback systems. The construction sector is particularly poor in using robust and reliable feedback systems. System dynamics was used as a tool to address complexity and process relationships, based on non-linear feedback. A model was developed to improve the management of information flow, using cloud computing technology and cloud collaboration tools for SMEs on construction sites. The model is useful for the specialty contractors, it provides a system and procedures with feedback loops that has the potential to provide and capture real-time information on performance and productivity.

\section{System dynamics model}

SD modelling tools consist of causal loop diagrams (CLDs), and stock and flow diagram (SFDs). CLDs are an important tool that represents the feedback structure of systems. It 
[To cite this article: Khurram lqbal Ahmad Khan, Roger Flanagan \& Shu-Ling Lu (2016), Managing information complexity using system dynamics on construction projects, Construction Management and Economics, DOI: 10.1080/01446193.2016.1190026]

consists of variables that are connected by arrows representing causal influences among the variables. These can be either negative (balancing) feedback or positive feedback (reinforcing) loops. Stocks are accumulations and depict the state of the system that generates information upon which decisions and actions are based (Sterman 2000). Figure 2 shows a causal loop diagram (CLD).

$<<$ Insert Figure 2 here $>>$

The CLD is based on the findings from the process maps derived from the data flow diagrams (DFDs). The information management variables are grouped in 'Project Information'; the variables affecting productivity on site are grouped in the 'SMEs Production, ' and the variables for the absorption of IT collaboration technologies consists of 'Cloud Computing Technology.' Six important loops are described:

\section{Reinforcing loop R1: complexity reduction}

In the causal loop diagram, the reinforcing loop (R1) shows that an increase in 'Project Information' leads to an increase in 'information complexity reduction' and an increase in 'information complexity reduction' leads to a corresponding increase in 'Project Information' thereby improving information flow on construction site.

\section{Balancing loop B1: complexity augmentation}

The balancing loop (B1) shows that a decrease in 'Project Information' leads to an increase in 'information complexity augmentation', which leads to a further decrease in 'Project Information' on construction site affecting productivity. 
[To cite this article: Khurram lqbal Ahmad Khan, Roger Flanagan \& Shu-Ling Lu (2016), Managing information complexity using system dynamics on construction projects, Construction Management and Economics, DOI: 10.1080/01446193.2016.1190026]

\section{Balancing loop B2: cloud technology absorption}

The balancing loop (B2) implies that a decrease in 'Project Information' prompts the SME to absorb technology shown by the causal link 'technology being absorbed', which eventually leads to the absorption of 'Cloud Computing Technology', including cloud collaboration tools. 'Cloud Computing Technology' absorption increases the 'information complexity reduction', which increases the 'Project Information' flow on site. There is an exogenous influence, the cost of the cloud computing technology shown by 'technology cost'; the cost being negligible does not affect the SME in the absorption of cloud computing technology.

\section{Balancing loop B3: cloud requirement}

The balancing loop (B3) shows that a decrease in the level of 'Cloud Computing Technology' due to an increase in 'technology being absorbed' leads to more requirement of cloud technology which leads to a further decrease in the 'Cloud Computing Technology'.

\section{Reinforcing loop R2: productivity improvement}

The reinforcing loop (R2) shows an increase in 'Project Information' flow facilitated by 'Cloud Computing Technology' which results in an increase in 'producing' levels leading to productivity improvement resulting in an increase in 'SMEs Production' on construction site. An increase in 'SMEs Production' leads to an increase in the 'information complexity reduction', and closes the feedback loop.

\section{Reinforcing loop R3: productivity level}


[To cite this article: Khurram lqbal Ahmad Khan, Roger Flanagan \& Shu-Ling Lu (2016), Managing information complexity using system dynamics on construction projects, Construction Management and Economics, DOI: 10.1080/01446193.2016.1190026]

The reinforcing loop (R3) shows that an increase in 'SMEs Production' leads to an increase in the 'producing' levels with productivity improvement resulting in further increase in 'SMEs Production' on site.

The causal loop diagram (CLD) provides a representation of information complexity and measures to manage the complexity through the improvement of project information flow. The CLD forms the basis for the system dynamics (SD) model. The CLD was mapped into the SD model using Stella Professional 1.0.3 software.

Figure 3 shows the stock and flow diagrams with feedback structure, and three main components, 'Cloud Computing Technology', 'Project Information', and 'SMEs Production'.

$<<$ Insert Figure 3 here $>>$

The SD model shows that the absorption of cloud computing technology (including cloud collaboration tools) increases project information flow, with digital devices, such as smart phones, tablets, phablets and laptops.

\section{Simulation results and discussion}

The model has three main components: 'Cloud Computing Technology', 'Project Information', and 'SMEs Production'. The simulation represents the behaviour over time graph (see Figure 4) which illustrates the absorption of 'Cloud Computing Technology' over a time period of sixty days, which can be adjusted according to requirements. The graphical curve is a draining process which implies that the outflow is greater than the inflow. The 
[To cite this article: Khurram lqbal Ahmad Khan, Roger Flanagan \& Shu-Ling Lu (2016), Managing information complexity using system dynamics on construction projects, Construction Management and Economics, DOI: 10.1080/01446193.2016.1190026]

'Cloud Computing Technology' is maximum at (0) days, however, due to absorption it reaches a minimum before it reaches (60) days.

\section{$<<$ Insert Figure 4 here >>}

Figure 5 represents the behaviour over time, illustrating the corresponding increase of 'Project Information' due to absorption of 'Cloud Computing Technology'. The graphical curve is known as a higher goal-seeking curve, which implies that the inflow is greater than the outflow. The 'Project Information' is minimum at (0) days, however, due to 'Cloud Computing Technology' absorption, it reaches a maximum before (60) days.

\section{$<<$ Insert Figure 5 here $>>$}

Figure 6 shows that an increase in absorption of 'Cloud Computing Technology' results in an increase in 'Project Information' leading to productivity improvement, with an increase in 'SMEs Production'. The graphical curve is a compounding process which represents an exponential growth. The 'SMEs Production' is minimum at (0) days; however, due to absorption of 'Cloud Computing Technology' there is an increase in 'Project Information', resulting in an increase in 'SMEs Production' reaching a maximum at (60) day. 
[To cite this article: Khurram lqbal Ahmad Khan, Roger Flanagan \& Shu-Ling Lu (2016), Managing information complexity using system dynamics on construction projects, Construction Management and Economics, DOI: 10.1080/01446193.2016.1190026]

\section{Conceptual framework for work packages for SMEs}

The project scope and deliverables are divided into smaller, more manageable parts. This process continues until the deliverables are small enough to be considered as 'work packages'. Work packages are placed at the lowest level of the work breakdown structure (WBS). The WBS is a hierarchical decomposition of the entire scope of work to be executed by the project team (PMI 2013). There is generally a high level of fragmentation in work packages. The main/principal contractor plans the project into a series of defined work packages, suitable for obtaining tenders and placing orders with the specialty contractors and the supply chain (BIS 2013).

A construction plan / programme is created showing various activities on site of the work package specialty contractor. The work package information generally lacks detail about the package programme time, details of access, relationship with other packages, sequence, and method of work. This leads to the development of a programme that is not detailed and accurate, which may cause delay leading to contractual claims, disputes, and change orders affecting the specialty contractors' budget, quality, and timely completion. Failure to complete can delay subsequent work packages and overall project completion.

Table 1 provides an example of a work package breakdown structure on a project. The example is not definitive or exhaustive, but for guidance purposes. 
[To cite this article: Khurram lqbal Ahmad Khan, Roger Flanagan \& Shu-Ling Lu (2016), Managing information complexity using system dynamics on construction projects, Construction Management and Economics, DOI: 10.1080/01446193.2016.1190026]

A conceptual framework is proposed (see Figure 7) in the form of a process map for SMEs. The framework starts with the main / principal contractor, breaking down the project scope into numerous work packages. Table 1 shows a list of different work packages. The work packages are interdependent, either in parallel or in sequence. Specialty contractors need detailed information relevant to their work package.

It consists of elements from the 'Factors' category (see Mapping the construction process). The 'SME work package information' consists of information related to the work package from design to production. It reflects the elements from the findings of the process maps shown in the 'Production' category (see Mapping the construction process). Specialty contractors often deal with excessive uncertainty, they plan, price and resource the work package based on insufficient, incomplete, and uncertain information, making assumptions that are not correct. Such wrong assumptions impact the level of complexity to be managed.

Every project has different levels of complexity. System dynamics (SD) helps to manage the complexity by identifying the critical factors. The framework suggests the use of SD (see 'Enablers' in 'Mapping the construction process') for the management of information complexity and process relationships based on non-linear feedback. The simulations provide behaviour over time graphs for different variables, reducing complexity and help in better decision-making. SD unravels information complexity and leads to 'dynamic planning'. The SME plan/programme developed is dynamic and flexible, and can manage changes to programme. It suggests to 'address communication and co-ordination' through the absorption of cloud computing (see 'Enablers') as a technology for enabling collaboration. It provides a platform for various collaboration software that facilitate effective information and data 
[To cite this article: Khurram lqbal Ahmad Khan, Roger Flanagan \& Shu-Ling Lu (2016), Managing information complexity using system dynamics on construction projects, Construction Management and Economics, DOI: 10.1080/01446193.2016.1190026]

transfer ensuring increased information mobility through seamless exchange of information and data in real-time. The information and data can be accessed using digital devices.

The specialty contractors benefit from working on a common data platform providing access to timely, and relevant information, with increased collaboration across the stakeholders including consultants and contractors. It can provide real-time feedback about project information and reduce errors, rework, delays, the likelihood of disputes and contractual claims. Improved work package information flow leads to productivity improvement, improved performance, and the possibility of increased profitability.

$<<$ Insert Figure 7 here $>>$

\section{Conclusions}

There is a need to manage information complexity for performance improvement for SMEs. System Dynamics (SD) was used to manage information complexity using collaboration technologies for SMEs. SD model was developed to help improve project information flow, leading to productivity improvement. The strength of the SD model lies in its robust feedback mechanism using cloud computing technology as an enabler. The SD model provides a system and procedures with feedback loops, with the potential to provide and capture realtime information on performance and productivity. The information feedback can be utilised on construction projects.

A conceptual framework was proposed for the specialty contractors to improve work package information and document management using system dynamics and cloud computing. The framework helps to improve productivity, and performance for the specialty contractors. 
[To cite this article: Khurram lqbal Ahmad Khan, Roger Flanagan \& Shu-Ling Lu (2016), Managing information complexity using system dynamics on construction projects, Construction Management and Economics, DOI: 10.1080/01446193.2016.1190026]

To understand a complex problem, the focus must be on the relationships and

interconnectivity in the whole system, not only on the constituent parts of the system. System dynamics provides a basis for understanding the management of complexity for the accessibility to information by SMEs.

The research has important practical implications, which include the use of system dynamics to help understand and address information complexity, and absorption of cloud computing to enable collaboration empowering the SMEs to increase their productivity and overall performance. 
[To cite this article: Khurram lqbal Ahmad Khan, Roger Flanagan \& Shu-Ling Lu (2016), Managing information complexity using system dynamics on construction projects, Construction Management and Economics, DOI: 10.1080/01446193.2016.1190026]

\section{References}

Andresen, J L (2000) The unidentified value of IT in the construction industry. In, The International Conference on Construction Information Technology, 17-18 January, 2000, Hong Kong Polytechnic University, 93-105.

Baccarini, D (1996) The concept of project complexity - a review. International Journal of Project Management, 14(4), 201-4.

Bawden, D and Robinson, L (2015) "Waiting for carnot": Information and complexity. Journal of the Association for Information Science and Technology, 66(11), 2177-86.

Beach, T H, Rana, O F, Rezgui, Y and Parashar, M (2013) Cloud computing for the architecture, engineering \& construction sector: Requirements, prototype \& experience. Journal of Cloud Computing, 2(1), 1-16.

Bertelsen, S (2003a) Complexity: Construction in a new perspective. In, 11th International Group for Lean Construction Conference Blacksburg, Virginia - USA, Vol. 11.

Bertelsen, S (2003b) Construction as a complex system. In, 11th International Group for Lean Construction Conference, Blacksburg, Virginia - USA, Vol. 11.

Betts, M (1999) Strategic management of IT in construction. UK: Wiley-Blackwell.

Bowden, S, Dorr, A, Thorpe, T and Anumba, C (2006) Mobile ICT support for construction process improvement. Automation in Construction, 15(5), 664-76.

Chen, Y and Kamara, J (2008) The mechanisms of information communication on construction sites. FORUM Ejournal, 8(1), 1-32.

Cheng, J C and Kumar, B (2012) Cloud computing support for construction collaboration. In: Anumba, C and Wang, X (Eds.), Mobile and pervasive computing in construction, pp. 237-54. UK: John Wiley \& Sons Ltd.

Dangerfield, B, Green, S and Austin, S (2010) Understanding construction competitiveness: The contribution of system dynamics. Construction Innovation: Information, Process, Management, 10(4), 408-20.

Department for Business Innovation \& Skills (2014) Business population estimates for the UK and regions 2014. In, UK: BIS Statistical Release.

Department for Business Innovation \& Skills (2013) Supply chain analysis into the construction industry-a report for the construction industrial strategy. In, UK: BIS.

Di Tommaso, M R and Dubbini, S (2000) Towards a theory of the small firm: Theoretical aspects and some policy implications. Santiago, Chile: United Nations Publications. 
[To cite this article: Khurram lqbal Ahmad Khan, Roger Flanagan \& Shu-Ling Lu (2016), Managing information complexity using system dynamics on construction projects, Construction Management and Economics, DOI: 10.1080/01446193.2016.1190026]

Forrester, J W (1961) Industrial dynamics. Cambridge, MA: MIT Press.

Forrester, J W (2003) Economic theory for the new millennium. In, 21st International Conference of the System Dynamics Society, 20-24 July, 2003, New York. The System Dynamics Society.

Grimes, C F (2006) Employee motivation, the organizational environment and productivity. London: Accel-Team.

Han, Q and Gani, A (2012) Research on mobile cloud computing: Review, trend and perspectives. In, Second International Conference on Digital Information and Communication Technology and it's Applications (DICTAP), 16-18 May 2012, Bangkok. IEEE, 195-202.

Hayden, F G (2006) The inadequacy of forrester system dynamics computer programs for institutional principles of hierarchy, feedback, and openness. Journal of Economic Issues, 40(2), 527-35.

Health \& Safety Executive (2002) Revitalising health and safety in construction :

Construction workers are six times more likely to be killed at work than other workers; discussion document. UK: Health and Safety Executive.

Hunt, V D (1996) Process mapping: How to reengineer your business processes. New York: John Wiley \& Sons.

Juan, D and Zheng, Q (2014) Cloud and open bim-based building information interoperability research. Journal of Service Science and Management, 7(2), 47-56.

Keys, P (1990) System dynamics as a systems-based problem-solving methodology. Systems practice, 3(5), 479-93.

Lane, D C (2000) Should system dynamics be described as a'hard' or'deterministic' systems approach? Systems Research and Behavioral Science, 17(1), 3-22.

Langford, D A and Male, S (1991) Strategic management in construction. Gower, London.

Le Vie, D S and Donald, S (2000) Understanding data flow diagrams. In, Annual Conference -Society for Technical Communication, Vol. 47, 396-401.

Marsh, L and Flanagan, R (2000) Measuring the costs and benefits of information technology in construction. Engineering Construction and Architectural Management, 7(4), 42335.

McGraw-Hill Construction (2013) Information mobility: Improving team collaboration through movement of project information, smartmarket report. New York: McGrawHill. 
[To cite this article: Khurram lqbal Ahmad Khan, Roger Flanagan \& Shu-Ling Lu (2016), Managing information complexity using system dynamics on construction projects, Construction Management and Economics, DOI: 10.1080/01446193.2016.1190026]

Mell, P and Grance, T (2011) The NIST definition of cloud computing, National Institute of Standards and Technology, Gaithersburg, MD, Special Publication 800-145.

Merry, U and Kassavin, N (1995) Coping with uncertainty: Insights from the new sciences of chaos, self-organization, and complexity. Praeger Publishers/Greenwood Publishing Group.

Miles, M B and Huberman, A M (1994) Qualitative data analysis: An expanded sourcebook. 2nd ed. Thousand Oaks, CA: Sage publications, Inc.

Morel, B and Ramanujam, R (1999) Through the looking glass of complexity: The dynamics of organizations as adaptive and evolving systems. Organization Science, 10(3), 27893.

Pallis, G (2010) Cloud computing: The new frontier of internet computing. IEEE Internet Computing, 14(5), 70-3.

Pekuri, A, Haapasalo, H and Herrala, M (2011) Productivity and performance managementmanagerial practices in the construction industry. International Journal of Performance Measurement, 1(1), 39-58.

Peters, S (2004) Information mobility: The behavioural technoscape. In, Alternative Mobility Futures Conference, Lancaster, UK.

Project Management Institute (2013) A guide to the project management body of knowledge (pmbok® guide). PA, USA: Project Management Institute.

Ramalingam, B, Jones, H, Reba, T and Young, J (2008) Exploring the science of complexity: Ideas and implications for development and humanitarian efforts. Vol. 285, London: Overseas Development Institute.

Richardson, K A, Cilliers, P and Lissack, M (2000) Complexity science: A 'grey'science for the 'stuff in between'. In, Proceedings of the First International Conference on Systems Thinking in Management, 8-10 November, 2000, Geelong, Australia 532-7.

Richmond, B (1994) Systems thinking/system dynamics: Let's just get on with it. System Dynamics Review, 10(2-3), 135-57.

Royal Institution of Chartered Surveyors (2013) NRM 2:Detailed measurement for building works. Coventry, UK: RICS.

Senge, P M (1990) The fifth discipline: The art and practice of the learning organization. Lincoln: Century Books. 
[To cite this article: Khurram lqbal Ahmad Khan, Roger Flanagan \& Shu-Ling Lu (2016), Managing information complexity using system dynamics on construction projects, Construction Management and Economics, DOI: 10.1080/01446193.2016.1190026]

Sexton, M and Barrett, P (2003a) A literature synthesis of innovation in small construction firms: Insights, ambiguities and questions. Construction Management and Economics, 21(6), 613-22.

Sterman, J D (2000) Business dynamics: Systems thinking and modeling for a complex world. USA: Irwin/McGraw-Hill Boston.

Sterman, J D (2001) System dynamics modeling. California management review, 43(4), 8-25.

Sterman, J D (2002) System dynamics: Systems thinking and modelling for a complex world. In, Proceedings of the ESD Internal Symposium, MIT, Cambridge, MA.

Titus, S and Bröchner, J (2005) Managing information flow in construction supply chains. Construction Innovation, 5(2), 71-82.

Wood, H L and Gidado, K (2008) An overview of complexity theory and its application to the construction industry. In: Dainty, A (Ed.), Procs 24th Annual ARCOM Conference, 1-3 September, 2008, Cardiff, UK. Association of Researchers in Construction Management, 677-86. 
[To cite this article: Khurram lqbal Ahmad Khan, Roger Flanagan \& Shu-Ling Lu (2016), Managing information complexity using system dynamics on construction projects, Construction Management and Economics, DOI: 10.1080/01446193.2016.1190026]

Table 1 Typical example of work packages for building construction (RICS 2013, p.37)

\begin{tabular}{|c|c|}
\hline Serial no. & Work Package Title \\
\hline 1. & Preliminaries \\
\hline 2. & Intrusive investigations \\
\hline 3. & Demolition works \\
\hline 4. & Groundworks \\
\hline 5. & Piling \\
\hline 6. & Concrete works \\
\hline 7. & Roof coverings and roof drainage \\
\hline 8. & External and internal structural walls \\
\hline 9. & Cladding \\
\hline 10. & Windows and external doors \\
\hline 11. & Mastic and sealants \\
\hline 12. & Non-structural walls and partitions \\
\hline 13. & Joinery \\
\hline 14. & Suspended ceilings \\
\hline 15. & Architectural metalwork \\
\hline 16. & Tiling \\
\hline 17. & Painting and decorating \\
\hline 18. & Floor coverings \\
\hline 19. & Fittings, furnishings \\
\hline 20. & Combined mechanical, electrical engineering and plumbing services \\
\hline 21. & External works \\
\hline
\end{tabular}


[To cite this article: Khurram Iqbal Ahmad Khan, Roger Flanagan \& Shu-Ling Lu (2016), Managing information complexity using system dynamics on construction projects, Construction Management and Economics, DOI:
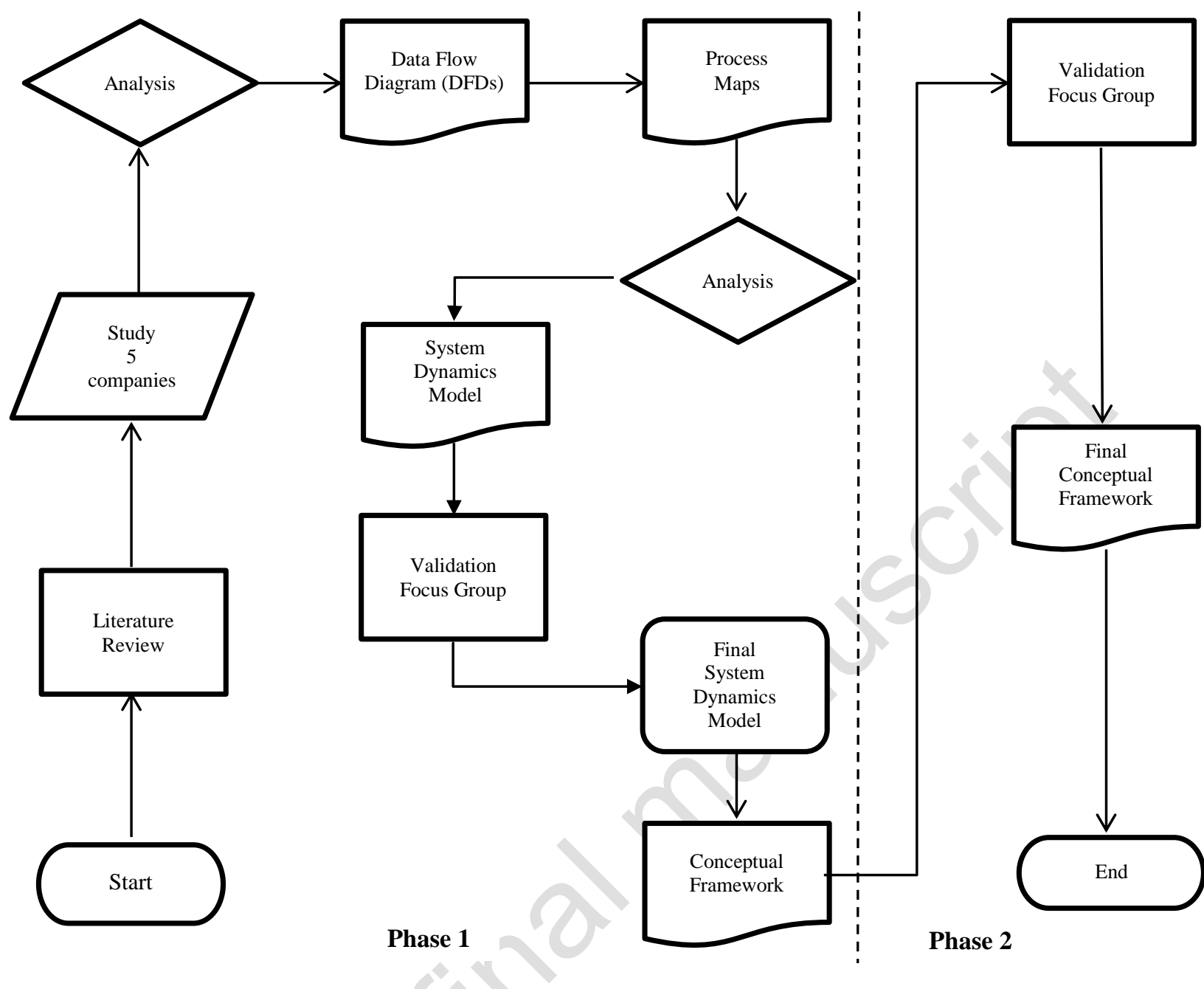

Phase 2

Figure 1 Research design protocol 
[To cite this article: Khurram lqbal Ahmad Khan, Roger Flanagan \& Shu-Ling Lu (2016), Managing information complexity using system dynamics on construction projects, Construction Management and Economics, DOI: 10.1080/01446193.2016.1190026]

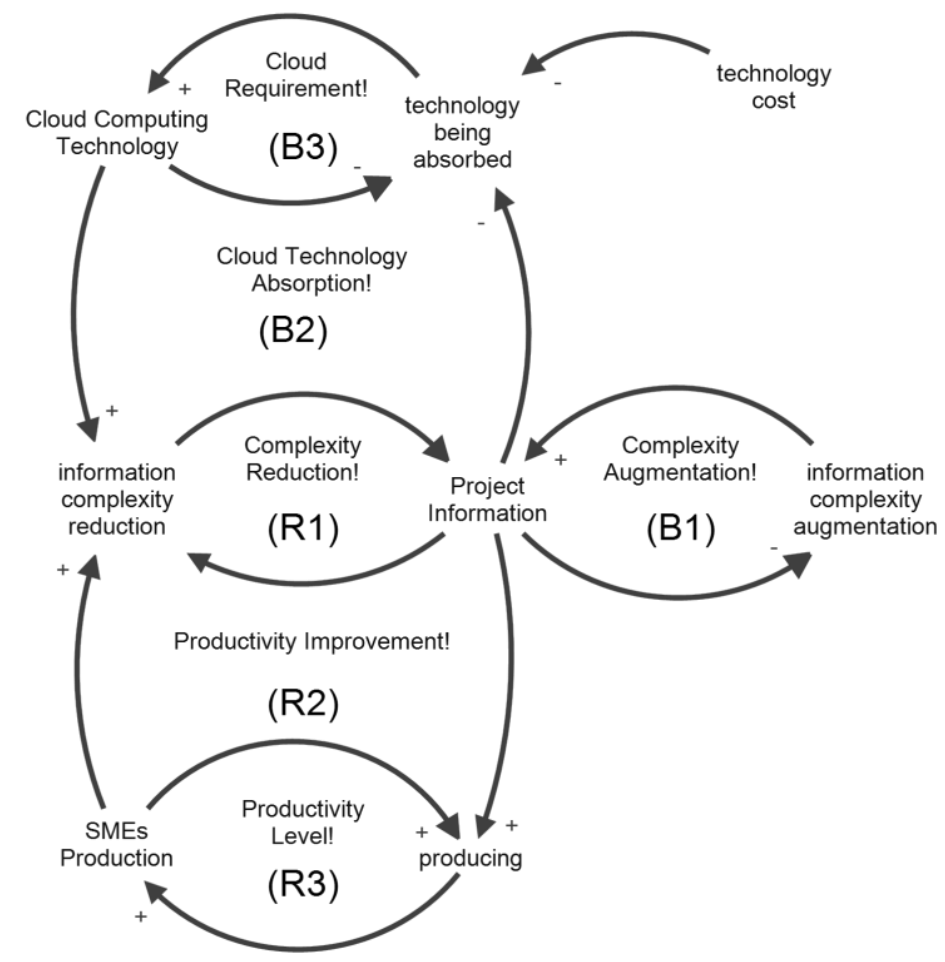

Figure 2 Causal loop diagram (CLD) 
[To cite this article: Khurram lqbal Ahmad Khan, Roger Flanagan \& Shu-Ling Lu (2016), Managing information complexity using system dynamics on construction projects, Construction Management and Economics, DOI: 10.1080/01446193.2016.1190026]

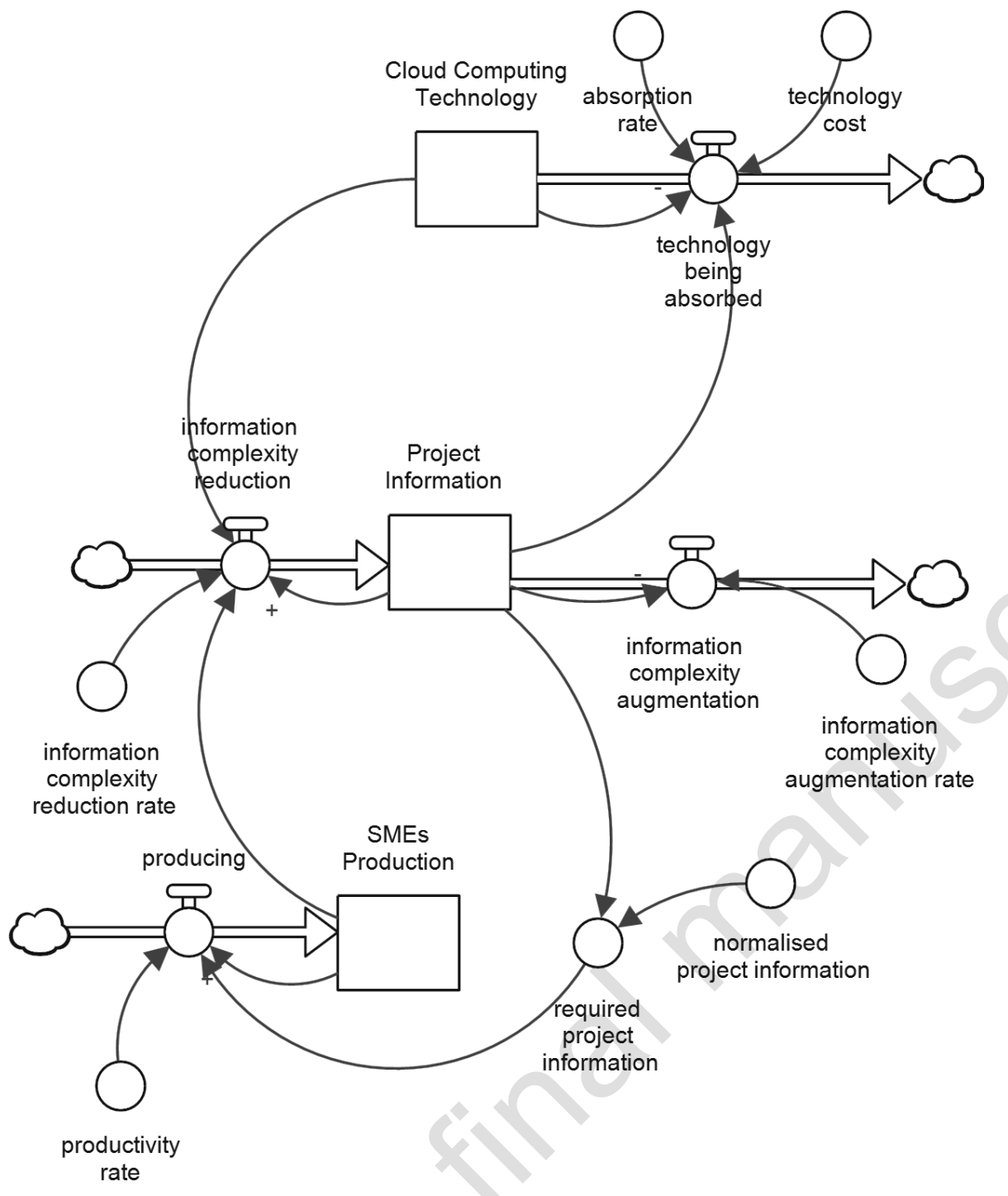

Figure 3 System dynamics model 
[To cite this article: Khurram Iqbal Ahmad Khan, Roger Flanagan \& Shu-Ling Lu (2016), Managing information complexity using system dynamics on construction projects, Construction Management and Economics, DOI: 10.1080/01446193.2016.1190026]

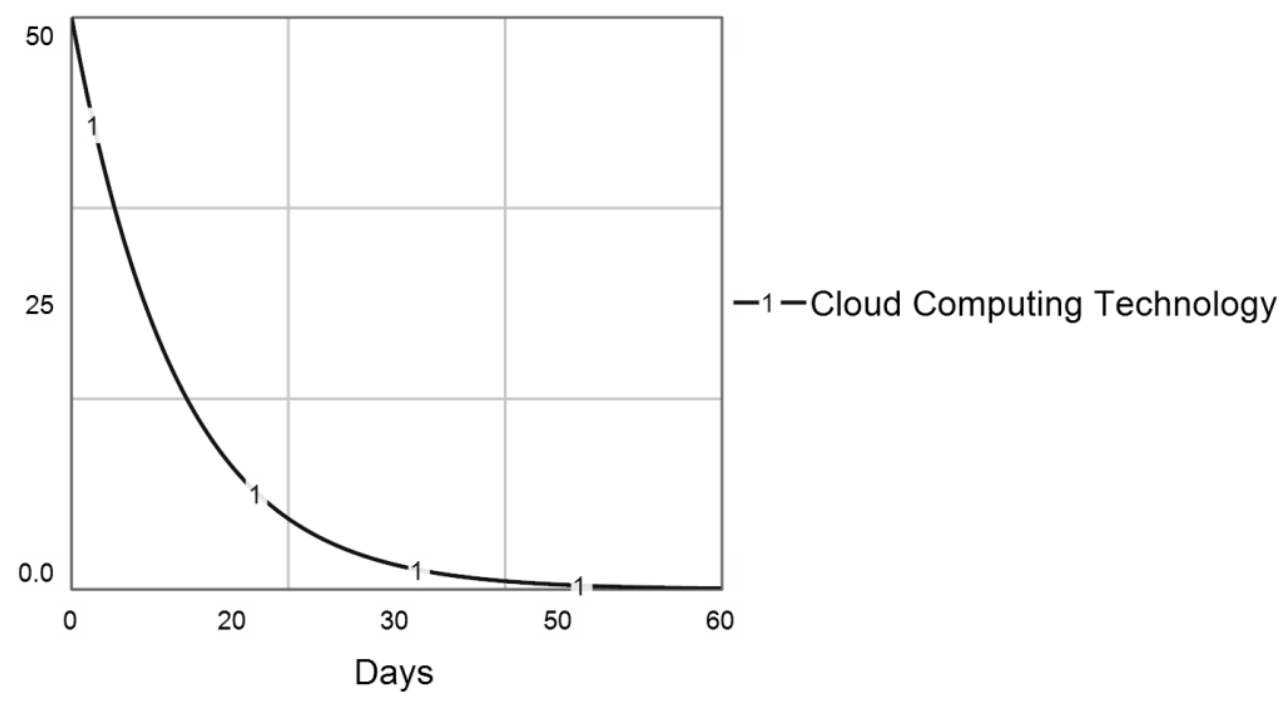

Figure 4 Cloud computing technology 
[To cite this article: Khurram Iqbal Ahmad Khan, Roger Flanagan \& Shu-Ling Lu (2016), Managing information complexity using system dynamics on construction projects, Construction Management and Economics, DOI: 10.1080/01446193.2016.1190026]

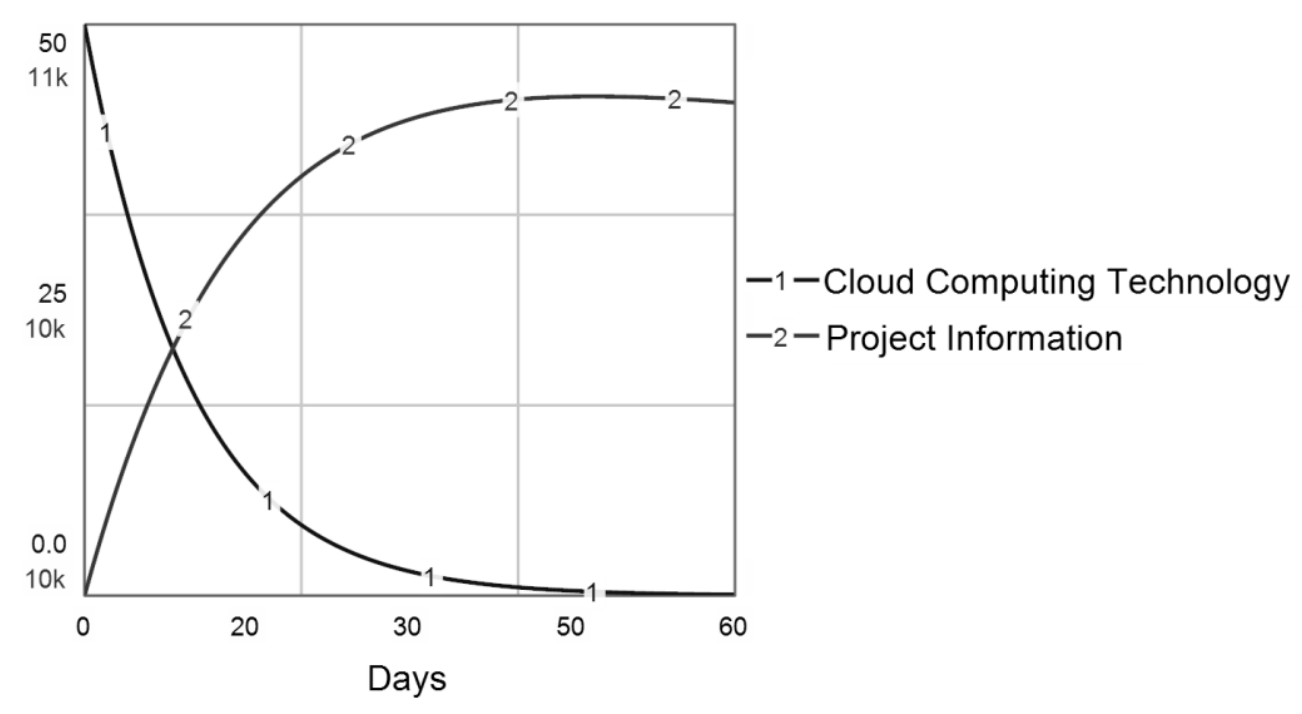

Figure 5 Project information 
[To cite this article: Khurram Iqbal Ahmad Khan, Roger Flanagan \& Shu-Ling Lu (2016), Managing information complexity using system dynamics on construction projects, Construction Management and Economics, DOI: 10.1080/01446193.2016.1190026]

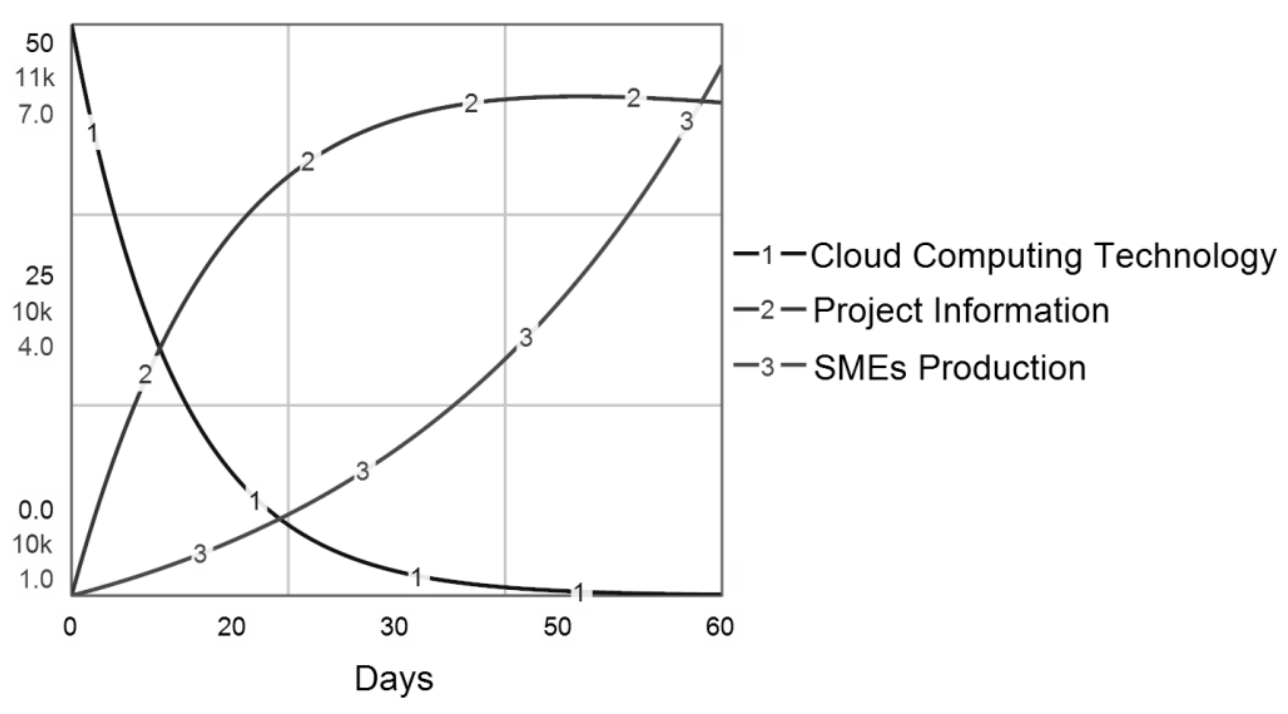

Figure 6 SMEs production 
[To cite this article: Khurram lqbal Ahmad Khan, Roger Flanagan \& Shu-Ling Lu (2016), Managing information complexity using system dynamics on construction projects, Construction Management and Economics, DOI: 10.1080/01446193.2016.1190026]

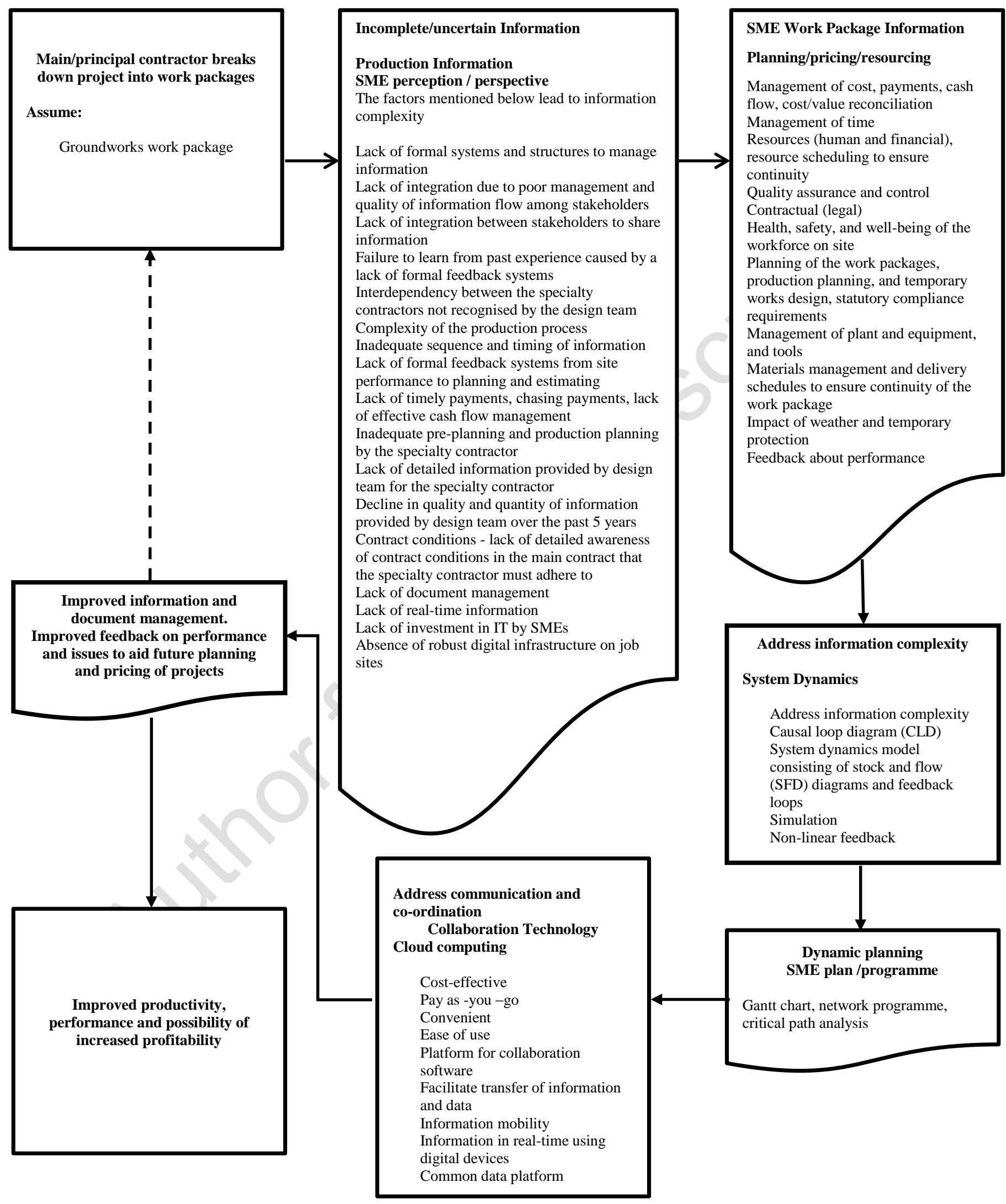

Figure 7 Conceptual framework for SMEs 